\title{
Role of diode laser in oral submucous fibrosis
}

\author{
Ramesh Kunusoth ${ }^{1, *}$, Aditya Mohan Alwala ${ }^{2}$, Rathod Prakash ${ }^{3}$, Porika Madhav Naik $^{4}$, Mudavath Anand ${ }^{5}$ \\ ${ }^{1,2}$ Associate Professor, ${ }^{3-5}$ Assistant Professor, ${ }^{1-3,5}$ Dept of Oral and Maxillofacial Surgery, ${ }^{4}$ Dept. of Orthodontics and Dentofacial \\ Orthopedic, MNR Dental College and Hospital, Telangana, India \\ *Corresponding Author: Ramesh Kunusoth \\ Email: rameshmaxillofacialsurgeon@ gmail.com
}

\begin{abstract}
Introduction: Oral submucous fibrosis is a precancerous condition affecting the oral cavity, oro-pharynx and rarely esophagus, tongue and commonly seen in those consuming betel nut. Its incidence has been reported $0.5 \%$ of the Indian population with a $7.6 \%$ potential for development of oral malignancy. Although various treatment modalities like medical and surgical are available, but there no single specific treatment modality for this condition.
\end{abstract}

Case Report: A male patient of age 45-year-old diagnosed with oral submucous fibrosis was treated with diode laser under local anesthesia and followed for three months.

Conclusion: Excision of the fibrous bands done by using diode laser followed by covering of collagen sheath on the raw surface of buccal mucosa gives uneventful healing with satisfactory results.

Keywords: Oral submucous fibrosis, Trismus, Diode laser.

\section{Introduction}

Oral submucous fibrosis (OSMF) is an oral precancerous condition characterized by chronic inflammation and progressive fibrosis of the submucosal tissues leading to stiffness of the mucosa causing difficulty in mouth opening. It is more prevalent in Indian subcontinent population and commonly seen in those consuming betel nut. Its incidence has been reported $0.5 \%$ of the Indian population with a $7.6 \%$ potential for development of oral malignancy. ${ }^{1,2}$

In India this rare entity was first described by Joshi in 1953, and its highest incidence with a prevalence rate of $2.5 \%$ was found in Kerala. In 1966, Pindborg JJ defined it as "an insidious chronic disease affecting any part of the oral cavity and sometimes the pharynx. Although occasionally preceded by and/or associated with vesicle formation, it is always associated with juxta-epithelial inflammatory reaction followed by a fibro elastic change of lamina propria, with epithelial atrophy leading to stiffness of oral mucosa and causing trismus and inability to eat". ${ }^{3}$

For the management of OSMF, a diversity of treatment modalities available like medical and surgical, rather than a specific single treatment modality. Patient counseling to quit the tobacco related habits is the foremost preventive measures for the management of OSMF. Based on the severity or marked mouth opening of the condition, conservative management such as usage of gold, ${ }^{4}$ antioxidants, hyluronidase, placental extract, vitamins, iron supplements, topical steroids like hydrocortisone, triamcinolone, and intralesional steroids is opted for mild to moderate cases with limitated mouth opening, ${ }^{5}$ Surgical management like scalpel surgical excision, laser excision and cryosurgery is opted for severe limitation of mouth opening or patients not responding to the conservative management, ${ }^{6}$ followed by dermal graft, ${ }^{7}$ tongue graft, ${ }^{8}$ nasolabial graft $^{9}$ etc. are in vogue to cover the surgical defect.
Considering the limited range of mouth opening, bleeding during the procedure which lack of accessibility and visibility in conventional surgical modality. In the present case we opted for laser treatment modality. In 1962, Goldman was the first person to introduced laser in dentistry, since then it has been widely used for the management of soft tissue lesions. The present case was reported to review the clinical prognosis of OSMF treated with diode laser. ${ }^{10}$

\section{Case Report}

A male patient of age 45-year-old reported to the department of oral and maxillofacial surgery with a chief complaint of restricted mouth opening and burning sensation on taking spicy food, since last three years. Patient revealed that he has the habit of smokeless tobacco consumption in the form of quid for last 16 years. Oral examination revealed pale and blanched appearance of buccal mucosa with palpable fibrous bands, leathery in texture, firm to hard in consistency, mildly tender. His preoperative mouth opening was $1.5 \mathrm{~cm}$. [Fig. 1] Based on history and clinical feature diagnosed as oral submucous fibrosis which further confirmed histologically. Patients consent was obtained after explaining the complete treatment procedure. The fibrous bands excised bilaterally by using diode laser under local anesthesia. [Fig. 2]

The boundary of the lesion was marked by using a pulse mode. The excision is carried out by diode laser $5 \mathrm{~W}$ per $\mathrm{cm}^{2}$ in continuous mode approximately $5 \mathrm{~mm}$ in depth and finally dissected with conventional method. [Fig. 3] Exposed raw surface is covered with collage nous sheath and suturing placed. [Fig. 4]

Patient was kept on symptomatic medication for one week and postoperative instructions were given such as physiotherapy and mouth exercise 6-7 times in a day at the interval of one hour, for a total period of 6 months. Mouth opening was monitored periodically at the interval of 1 
week, 1 month and 3 months. At the end of 3 months an observable mouth opening was noted around $2.9 \mathrm{~cm}$ with uneventful healing of the surgical site and complete remission of burning sensation was noted within a month. [Fig. 5]

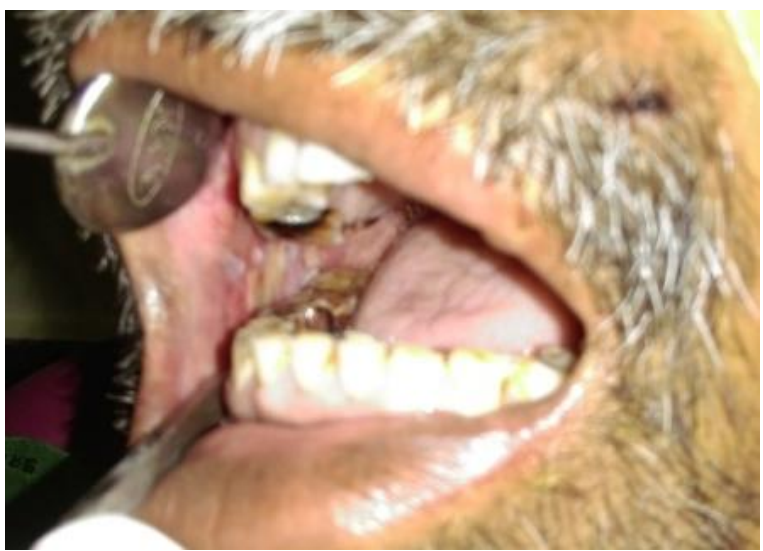

Fig. 1: Limited mouth opening

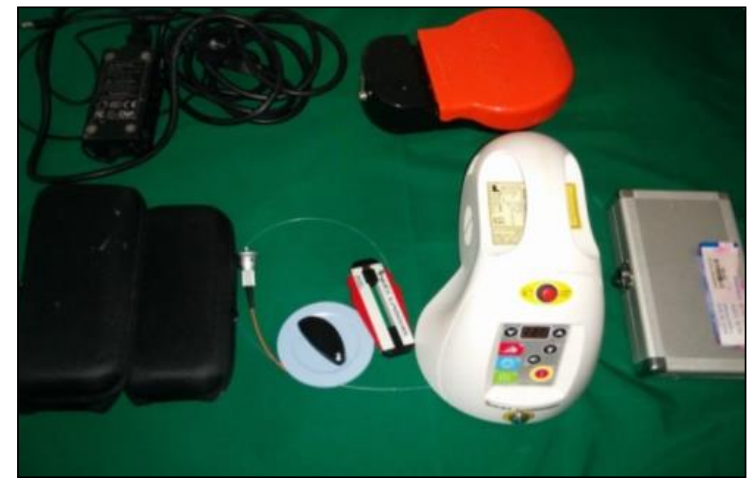

Fig. 2: Diode laser

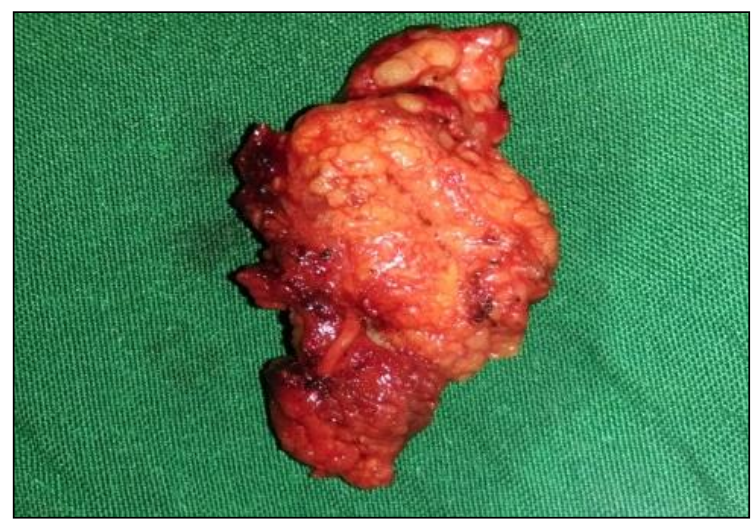

Fig. 3: Laser Excision specimen

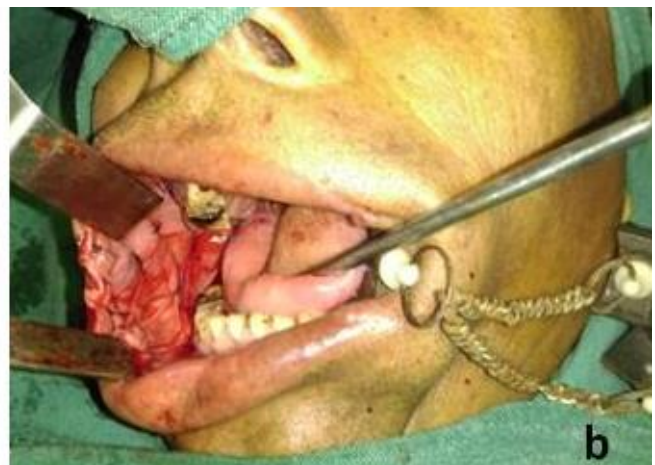

Fig. 4: collagenous sheath (a) Exposed raw surface closed with collagenous sheath, and suturing done (b)

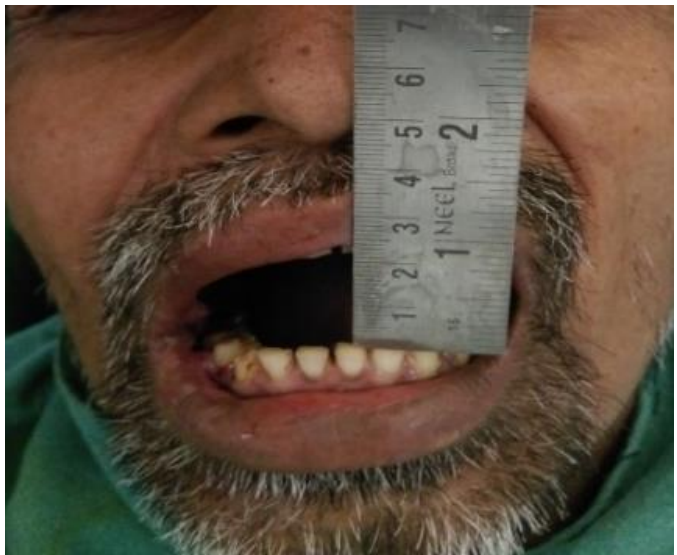

Fig. 5: Post operative mouth opening after 3 months

\section{Discussion}

OSMF is one of the most common premalignant conditions in India, which is an easy to diagnose but difficult to manage. It has also been referred to as an epidemic in India. ${ }^{11,12}$ Literature suggests variable gender distribution. Some epidemiological surveys in India have shown female predominance ${ }^{13,14}$ whereas other shows male predominance. ${ }^{15}$ The reason for younger age group and male predominance is due to marketing and easy availability of gutkha and other related tobacco products. ${ }^{15}$

The incidence has been reported to be $0.5 \%$ of the Indian population with a $7.6 \%$ potential for development of malignancy. ${ }^{1}$ Prevalence of precancerous lesions was found to be 21.9 per $1000 .^{11}$ 
Gutkha chewing produces OSMF earlier as compared to other smokeless tobacco habit forms. The reason for increased prevelance of OSMF in gutkha chewers is due to the abrasive nature and chemical content of areca nut such as arecoline, ${ }^{16,17}$ which is the main constituent of pan masala and gutkha, which causes continuous local trauma and irritation to the oral mucosa leading to morphological changes. ${ }^{16}$ Although smoking is not directly related to the development of OSMF, when patients have coexisting smoking habit along with smokeless form, this poses them to a high risk of malignant changes, as tobacco smoking has been reported to act jointly with betel quid in the genesis of oral and esophageal cancers. ${ }^{18}$

The exact etiology of this condition is not fully understood and its progressive nature. The management of OSMF is challenging for an oral physician and there is no specific single treatment modality documented, ranging from medical to surgical management. ${ }^{19}$ Considering the role of diode laser in the management of soft tissue lesions in the oral cavity and their role in management of OSMF reported in literature, the present case is treated with diode laser under local anesthesia and which rendered good results with significant mouth opening at the end of three months. ${ }^{19}$

\section{Conclusion}

Surgical management of OSMF with restricted mouth opening is a challenging task and needs meticulous planning and its execution by oral surgeons. Surgical management using diode laser should be encouraged in moderately advanced to advanced cases over conventional procedures. Advantage being laser creates précised incisional marks, an excellent cosmetic and functional result is achieved. Procedure is less time-consuming and more economical due to a shortened hospital stay which resulted in better patient satisfaction and compliance.

\section{References}

1. Pindborg JJ. Oral precancerous conditions in SE Asia. Int Dent J. 1965; 32:750.

2. Khanna, Andrade. OSMF a New concept in surgical management. Int J Oral Maxil Sur. 1995;24:433-439.

3. Gupta SC. "Mist" an etiological factor in oral submucous fibrosis. Ind J Otolaryngol. 1978;30(1):5-6.

4. Marawetz G, Katsikers N, Weinberg S, Listrom R. Oral submucous fibrosis. J Oral Maxillofac Surg. 1987;16:609-614.

5. Borle RM, SR Borle. Management of Oral Submucous Fibrosis: A conservative approach. J Oral Maxillofac Surg. 1991;49:788-789.

6. Khanna JN, Andrade NN. Oral submucous fibrosis: a new concept in surgical management. Report of 100 cases. Int $J$ Oral Maxillofac Surg. 1995;24:433-439.

7. Yen DJ. Surgical treatment of submucous fibrosis. J Oral Surg. 1982;269-272.

8. Golhar S, Manohar MN, Narkhede S. Tongue flap in oral submucous fibrosis. Ind J Otolaryngol. 1989;41:104-107.

9. Kavarana NM, Bhathena HM. Surgery for severe trismus in submucous fibrosis. Br J Plast Surg. 1987;40:407-409.

10. Balabaskaran K, Srinivasan A. Treatment Options for Oral Submucous Fibrosis. IOSR J Dent Med Sci (IOSR-JDMS). 2013;10:33-35.
11. Deshmukh PT, Raizada RM, Chaturvedi VN (1994) Epidemiological study of oral premalignant lesions in 3460 rural inhabitants of Maharashtra state. In: Oral oncology. Vol. III A Research. Ed. Verma AK. 3rd International Congress on OC Epi India (1994) Des: Case-control study 1994, pp 44-6.

12. National Cancer Institute. Smokeless tobacco and cancer 2010. Retrieved from http://www.cancer.gov/cancertopics/factsheet/ tobacco/smokeless.

13. Gupta PC, Sinor PN, Bhonsle RB et al. Oral submucous fibrosis in India: a new epidemic? Natl Med J India. 1998;11:113-116.

14. Sinor P, Gupta P,Murti P, Bhonsle R, Daftary D, Mehta F, Pindborg J. A case control study of oral submucous fibrosis with special reference to the etiologic role of areca nut. J Oral Pathol Med. 1990;19:94-98.

15. Murti P, Gupta P, Bhonsle R, DaftaryD, Mehta F, Pindborg J. Effect on the incidence of oral submucous fibrosis of intervention in the areca nut chewing habit. J Oral Pathol Med. 1990;19:99-100.

16. Ali FM, Aher V, Prasant MC, Bhushan P, Mudhol A, Suryavanshi H. Oral submucous fibrosis: comparing clinical grading with duration and frequency of habit among areca nut and its products chewers. J Can Res Ther. 2013;9(3):471-476.

17. Macfarlane GJ, Zheng T, Marshall JR, Boffetta P, Niu S, Brasure J. Alcohol, tobacco, diet and the risk of oral cancer: a pooled analysis of three case-control studies. Eur J Cancer. 1995;31:181-187.

18. Lee CH, Lee JM, Wu DC et al. Independent and combined effects of alcohol intake, tobacco smoking and betel quid chewing on the risk of esophageal cancer in Taiwan. Int $J$ Cancer. 2005;113(3):475-82.

19. Asnani S, Mahindra U, Oswal R. Use of diode lasers in treatment of oral submucous fibrosis: A new concept in surgical management. IJCRI. 2014;5:198-201.

How to cite this article: Kunusoth $\mathrm{R}$, Alwala A. M, Prakash R, Naik P. M, Anand M. Role of diode laser in oral submucous fibrosis. J Oral Med, Oral Surg, Oral Pathol, Oral Radiol. 2018;4(4):198-200. 